Journal of Animal and Veterinary Advances 11 (13): 2196-2203, 2012

ISSN: $1680-5593$

(C) Medwell Journals, 2012

\title{
Culture of Chicken Gonadal Primordial Germ Cells (gPGCs) in Chicken Embryonic Fibroblast (CEF) Cells Conditioned Medium and in vivo Migration
}

\author{
${ }^{1,2} \mathrm{Jenn}-\mathrm{Fa}$ Liou, ${ }^{2} \mathrm{Jen}-\mathrm{Wen}$ Shiau, ${ }^{2} \mathrm{Jui}-\mathrm{Jane}$ Tailiu, ${ }^{3} \mathrm{Chein}$ Tai, \\ ${ }^{1,2,3}$ Lih-Ren Chen and ${ }^{1}$ Ming-Cheng Chang \\ ${ }^{1}$ Institute of Biotechnology, National Chung Kung University, 701 Tainan, Taiwan, R.O. Chine \\ ${ }^{2}$ Physiology Division, Livestock Research Institute, COA-LRI, 712 Tainan, Taiwan, R.O. China \\ ${ }^{3}$ Southern Taiwan University, 710 Tainan, Taiwan, Taiwan, R.O. China
}

\begin{abstract}
The primitive gonads collected from 5.5 days old chicken embryos were dissociated and explanted onto plates pre-coated with $0.1 \%$ gelatin. The conditioned media from proliferating and Chicken Embryonic Fibroblast (CEF) cells was supplemented with growth factors and used to support the growth of gPGCs. The result showed that the conditioned media could promote the growth and colony formation of gPGCs in vitro in particular the conditioned by CEF cells. The gPGC derived colonies maintained in CEF cells-conditioned medium up to 281 days were positively antibodies specific to anti-SSEA-1, SSEA- 4 integrin $\alpha 6$ and integrin $\beta 1$ and stained by periodic acid Schiff reaction. Their capacities of migration via vascular system and taking up residence in the primary gonadal ridge were further demonstrated by transferring to the dorsal aorta of stage 17 recipient embryos. These results suggested that the culture system is able to maintain chicken gPGCs for long-term in vitro culture without losing their capacity to express pluripotent markers and to integrate into the gonads.
\end{abstract}

Key words: Chicken, Chicken Embryonic Fibroblast (CEF), gPGCs, migration, Schiff reaction

\section{INTRODUCTION}

Avian Primordial Germ Cells (PGCs) originate from the epiblast and give rise to gametes (Eyal-Giladi et al., 1981). As avian PGCs migrate into the embryonic gonads through the vascular system, it makes PGCs convenient to be harvested for genetic modification. It has been demonstrated that germline chimeras could be obtained by transplantation of chicken PGCs collected from germinal crescent (Wentworth et al., 1988; Petitte et al., 1990) and embryonic blood (Naito et al., 1994a, b).

However, collection of PGCs from such tissues is technically difficult and the number of available PGCs providing for transplantation is exceedingly limited (Park et al., 2003). Therefore, isolation and long-term culture of PGCs from the embryonic gonads might provide a plenty resource for genetic manipulation of the chicken. Allioli et al. (1994) first reported that chicken PGCs isolated from gonads could proliferate in vitro for several days. Park and Han (2000) established a longterm in vitro culture system for Chicken Gonadal PGCs (gPGCs). This report was first to develop and characterize Embryonic Germ (EG) cells in avians (Park and Han, 2000). They isolated gPGCs from the undifferentiated gonads of stage 28 chicken embryos and maintained in culture for
4 months. These gPGCs cultured on feeders of mitotically active Chicken Embryonic Fibroblasts (CEF) were both positively stained with SSEA-1 antibody and Periodic Acid-Schiff (PAS) reaction. Somatic and germline chimeric chicken were obtained by transfer of these cultured gPGCs to the sub-germinal cavity of recipient embryos at stage X. A similar in vitro system was used to culture chicken gPGCs with their own stroma cells for 2 months without subpassage and change of feeder cells and germline chimeras were also produced (Han et al., 2002). With the culture of pluripotent stem cells, it can not only provide sufficient materials for transgenic manipulation but allow the selection of cells that have integrated the transgene and cells to undergo targeted changes to the genome through selection of homologous recombination events (Capecchi, 2001; Lillico et al., 2005). In this study, researchers use conditioned media on the establishment of a long-term in vitro culture system that was convenient for the genetic manipulation of chicken gPGCs.

\section{MATERIALS AND METHODS}

Sources of chicken primordial germ cells and stroma cells: Animal care and experimental procedures used in this study were reviewed and approved by the Ethic

Corresponding Author: Ming-Cheng Chang, Institute of Biotechnology, National Chung Kung University, 701 Tainan, Taiwan, R.O. China 
Committee of Laboratory Animals at the Livestock Research Institute, Council of Agriculture, Taiwan. The gPGCs and stroma cells used in this study were prepared from gonads of white leghorn embryos at stage 28 (5.5 days of incubation).

Preparation of conditioned medium: The medium used to maintain chicken gPGCs was previously conditioned by CEF. Chicken embryonic fibroblast cells were prepared by primary culture of chicken embryos incubated for 5 days. The procedures to prepare conditioned medium were described as follows. Petri dishes were pre-coated with $0.1 \%$ gelatin (Sigma-Aldrich) solution. Chicken embryonic fibroblasts were plated at a concentration of $5 \times 10^{4}$ cells $\mathrm{mL}^{-1}$ on the $10 \mathrm{~cm}$ Petri dish in Dulbecco's Modified Eagle's Medium (DMEM; Invitrogen, Paisley, UK) containing 10\% Fetal Bovine Serum (FBS; Invitrogen), $2 \mathrm{~m} \mathrm{M} \mathrm{L}$-glutamine (Invitrogen), 100 units $\mathrm{mL}^{-1}$ penicillin

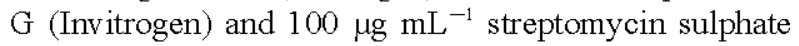
(Invitrogen). The cells were cultured at $37^{\circ} \mathrm{C}$ in $5 \% \mathrm{CO}_{2}$. As cells were confluent, the original culture medium was replaced with $10 \mathrm{~mL}$ of Embryonic Germ Cell culture medium (EGM) containing DMEM, 10\% FBS, 2\% chicken serum (Invitrogen), $1 \mathrm{mM}$ sodium pyruvate (SigmaAldrich), $2 \mathrm{mM}$ L-glutamine, $55 \mu \mathrm{M}$ 2-mercaptoethanol (Sigma-Aldrich), $100 \mu \mathrm{g} \mathrm{mL} \mathrm{m}^{-1}$ streptomycin sulphate and 100 units $\mathrm{mL}^{-1}$ penicillin $\mathrm{G}$. Collection of the conditioned medium and replacement of new EGM were performed at every $24 \mathrm{~h}$ intervals for $7-10$ days. The conditioned media collected from the same treatment were pooled, centrifuged at $200 \times \mathrm{g}$ for $5 \mathrm{~min}$ and filtered through a $0.22 \mu \mathrm{m}$ filter and then stored at $-20^{\circ} \mathrm{C}$ before use.

Isolation and in vitro culture of chicken gPGCs: Fertile eggs from white leghorn chicken were incubated for 5.5 days. Primitive gonads of the chicken embryos developed to stage 28 (Hamburger and Hamilton, 1951) were collected. The embryonic gonadal tissues were dissociated in $0.05 \%$ trypsin- $0.53 \mathrm{mM}$ EDTA by gentle pipetting. After neutralization of trypsin-EDTA with EGM, the gonadal cells were harvested by centrifugation at $200 \times \mathrm{g}$ for $5 \mathrm{~min}$.

The cell pellets were then resuspended and the cell concentration was adjusted to $4 \times 10^{4} \mathrm{~mL}^{-1}$ with each of the four conditioned media supplemented with growth factors (10 units $\mathrm{mL}^{-1}$ of human Leukaemia Inhibitory

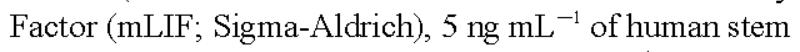
cell factor (hSCF; Sigma-Aldrich), $10 \mathrm{ng} \mathrm{mL}^{-1}$ of human basic fibroblast growth factor (hbFGF; Sigma-Aldrich), $10 \mathrm{ng} \mathrm{mL} \mathrm{mL}^{-1}$ of human insulin-like factor-I (hIGF-I; Sigma-Aldrich) and $0.04 \mathrm{ng} \mathrm{mL} \mathrm{m}^{-1}$ of human Interleukin-1 1 (hIL-11; Sigma-Aldrich)] and seeded onto gelatin-coated 4-well plates and cultured at $37^{\circ} \mathrm{C}$ in $5 \% \mathrm{CO}_{2}$. The medium was partially $(50 \%)$ changed every day. Colonies formed were regularly subcultured every 10-14 days. Passage of cultured gPGCs was performed by enzymatic dissociation with $0.05 \%$ trypsin- $0.53 \mathrm{mM}$ EDTA, harvested the cells by centrifugation, resuspended the cell pellet with fresh medium and reseeded the cell suspension into fresh 4-well plates.

PAS staining and alkaline phosphatase activity assay: The colonies of cultured chicken gPGCs were fixed to the plate in $1 \%$ glutaraldehyde for $5 \mathrm{~min}$ and rinsed twice with Phosphate-Buffered Saline (PBS; Sigma-Aldrich). For PAS staining, the fixed gPGCs were immersed in periodic acid solution (Sigma-Aldrich) for $5 \mathrm{~min}$ at room temperature. After washing twice with PBS, the fixed gPGCs were immersed in Schiff's solution (Sigma-Aldrich) for $15 \mathrm{~min}$ at room temperature. After washing twice with PBS, PAS-stained gPGC colonies were observed under the bright field of an inverted microscope. Alkaline Phosphatase (AP) activity was detected by AP substrate kit (Sigma-Aldrich) according to the manufacture's instruction.

Immunocytochemistry staining: The colonies of cultured chicken gPGCs were fixed to the plate in $1 \%$ glutaraldehyde for $5 \mathrm{~min}$ and rinsed twice in PBS. After blocking with $1 \% \mathrm{BSA}$ for $1.5 \mathrm{~h}$ at room temperature and washed with $\mathrm{PBS}$, the colonies were incubated overnight with appropriate dilution of primary antibody or combination of antibodies at $4^{\circ} \mathrm{C}$. Thereafter, the cells were washed with PBS and then incubated with the secondary antibody of the $1: 1000$ diluted biotinconjugated secondary antibody (AP128B; Chemicon, Temecula, CA, USA) for a minimum of $2 \mathrm{~h}$, followed by washing in PBS. Avidin/biotin-conjugated AP system (SA204; Chemicon) and BCIP/NBT AP substrate (ES0006; Chemicon) were used to detect the results. Primary antibodies used were specific against SSEA-1, SSEA-4 integrin $\beta 1$ and integrin $\alpha 6$, respectively. All the primary antibodies were purchased from Chemicon and hybrided in a 200 -fold dilution. Fluorescent cells were visualized using an inverted fluorescence microscopy (DM IRB; Leica, Wetzlar, Germany) equipped with digital camera (E995; Nikon, Tokyo, Japan). Negative controls for each fluorophore-conjugated secondary antibody were carried out without the addition of the primary antibody. There was no nonspecific binding of the secondary antibodies exhibited.

In vivo migration test for cultured gPGCs: To determine whether the gPGCs still had the property of migration through the vascular system into the embryonic gonads after long-term in vitro culture, gPGCs cultured for 253 days (passage 18) were used as donor cells for transplanting into the recipient chicken embryos. Colonies 
of cultured gPGCs were detached from gonadal stroma monolayer and mechanically dispersed into single cell suspension. Before transplantation, an EGFP reporter gene driven by CMV promoter (Clontech, Mountain view, CA, USA) was transferred into the gPGCs. Approximately, $2.5 \times 10^{5}$ gPGCs were mixed with $15 \mu$ g plasmids in $1 \mathrm{~mL}$ of Medium-199 supplemented with 10\% chicken serum and $1.32 \%$ DMSO.

Gene transfer of the cultured gPGCs was carried out in the $2 \mathrm{~mm}$ Gap Cuvette (BTX model 620) with one DC pulse of $150 \mathrm{~V} / \mathrm{cm}$ for $10 \mathrm{~ms}$ supplied by an ECM 2001 electroporator (BTX, Genetronics Inc., San Diego, CA, USA). Directly after electroporation, gPGCs were washed and resuspended in HBSS containing $1 \%$ penicillin/streptomycin (Invitrogen).

Approximately $3 \mu \mathrm{L}$ of electroporated gPGC suspension containing 300-350 cells $\mu \mathrm{L}^{-1}$ were injected into the dorsal aorta of each 3.5 days old embryo of the coloured Taiwan Country Chicken. Control cell transplantation was performed with the freshly isolated gPGCs from fertile eggs of White Leghorn chicken incubated for 5.5 days. These injected eggs were incubated to hatch. The gonads of the 19 days old chicks were isolated and subjected to frozen dissection and genomic DNA extracted. The isolated gonads were placed in $20 \%$ sucrose/PBS at $4^{\circ} \mathrm{C}$. The following day, the gonads were transferred to embedding compound and then snap frozen in isopentane pre-cooled in liquid nitrogen. Frozen sections ( $7 \mathrm{~mm}$ ) were thaw-mounted onto slides pre-treated with PBS and fixed in 10\% formaldehyde for $10 \mathrm{~min}$. After PBS washes, sections were permeablized in $1 \%$ Triton $\mathrm{X}-100 / \mathrm{PBS}$ for $10 \mathrm{~min}$ at room temperature and then washed with PBS for 3 times. Then, the sections were treated with $3 \% \mathrm{H}_{2} \mathrm{O}_{2}$ for $10 \mathrm{~min}$ and blocked in $5 \%$ FCS for $1 \mathrm{~h}$ at room temperature. Thereafter, the sections were incubated with rabbit anti-GFP polyclonal serum (1:200, A6455; Invitrogen) overnight at $4^{\circ} \mathrm{C}$. Sections were washed in PBS incubated with fluorescent labelled goat anti-rabbit secondary antibody (1:1000, A11034; Invitrogen) for $2 \mathrm{~h}$, mounted in Fluorosave (Calbiochem, Darmstadt, Germany) and examined under a fluorescence microscope.

The total DNA was extracted from gonads of the 19 days old chicks by the genomic DNA purification kit (Promega, WI, USA). The Polymerase Chain Reaction (PCR) analysis was carried out DNA samples in order to detect the presence of the GFP. The primer was designed: primer A1, 5'-GCTCAATCGAATTCTGC T-3' (sense) and primer A2, 5'-GAACTTCAGGGTCAGCTTGC -3' (antisense). After an initial denaturation step $(95,10 \mathrm{~min})$, the PCR was performed in a reaction mixture $(10 \mathrm{~L})$ containing $0.2 \mathrm{M}$ each of the primers, $1 \times \mathrm{PCR}$ buffer, $0.2 \mathrm{mM}$ dNTPs, $0.25 \mathrm{U}$ AmpliTaq Gold polymerase (Perkin
Elmer Applied Biosystems, Foster, USA) and 10 ng of DNA template. The amplification step consisted of 40 cycles denautration $\left(94^{\circ} \mathrm{C}, 30 \mathrm{sec}\right)$, annealing $\left(56^{\circ} \mathrm{C}\right.$, $30 \mathrm{sec})$ and extension reaction $\left(72^{\circ} \mathrm{C}, 1 \mathrm{~min}\right)$ before a final extension step of $10 \mathrm{~min}$ at 72 . The PCR products with a predicted size of 202 bp were analyzed by electrophoresis on $2 \%$ agarose gels.

\section{RESULTS AND DISCUSSION}

In the present study, the gPGCs were plated together with their own stroma cells as primary culture and the gonadal stroma cells were used directly as feeder cells. The gPGCs were composed of a large excentric nucleus and relatively small amount of cytoplasm with several granules. The gonadal stroma cells attached to the surface of the culture dish and slowly spread over as a monolayer within 5 days but did not form any colony. The gPGCs adhered and grew only on gonadal stroma cells and began to form colonies 7-10 days after plating (Fig. 1a). The chicken gPGC colonies did not tightly contact with the stroma monolayer. Furthermore, the individual cells onsisting in gPGC colonies did not firmly pack together into small nests and were easily to be distinguished. The gPGCs and their stroma cells were subcultured together at an interval of approximately 10-14 days. These chicken gPGC-derived colonies have been maintained in CEF for up to 22 passages and proliferated over 281 days (Fig. $1 \mathrm{~b}$ and c) in repeated subculture throughout this study. Transgenic hens, turning the common chickens into pharmaceutical bioreactors can meet the growing demand for protein-based human therapeutics (Lillico et al., 2005). The use of Primordial Germ Cells (PGCs) to produce germline chimeras provides numerous advantages for generating transgenic birds (Han, 2009). Germline chimeras have been successfully produced in domestic fowl by transferring PGCs or PGC-derived embryonic germ cells (Park et al., 2008) and researchers recently established transgenic quail lines (Shin et al., 2008) following PGC transfer into recipient embryos. Researchers initially plated gPGCs together with their own gonadal stroma cells as mixed cell populations. During the initial culture period, single or clump gPGCs were rare, although they had typical exocentric nucleus with small amount of cytoplasm and containing numerous glycogen granules that could be easily recognized by morphological difference (Fig. 1).

Alkaline Phosphatase (AP) activity is one of the characteristics of murine and porcine Embryonic Stem (ES) cells. However, gPGCs in the embryonic gonads and cultured gPGCs in present study showed very weak AP activity. The colonies derived from cultured chicken gPGCs could hardly be stained for AP expression. 

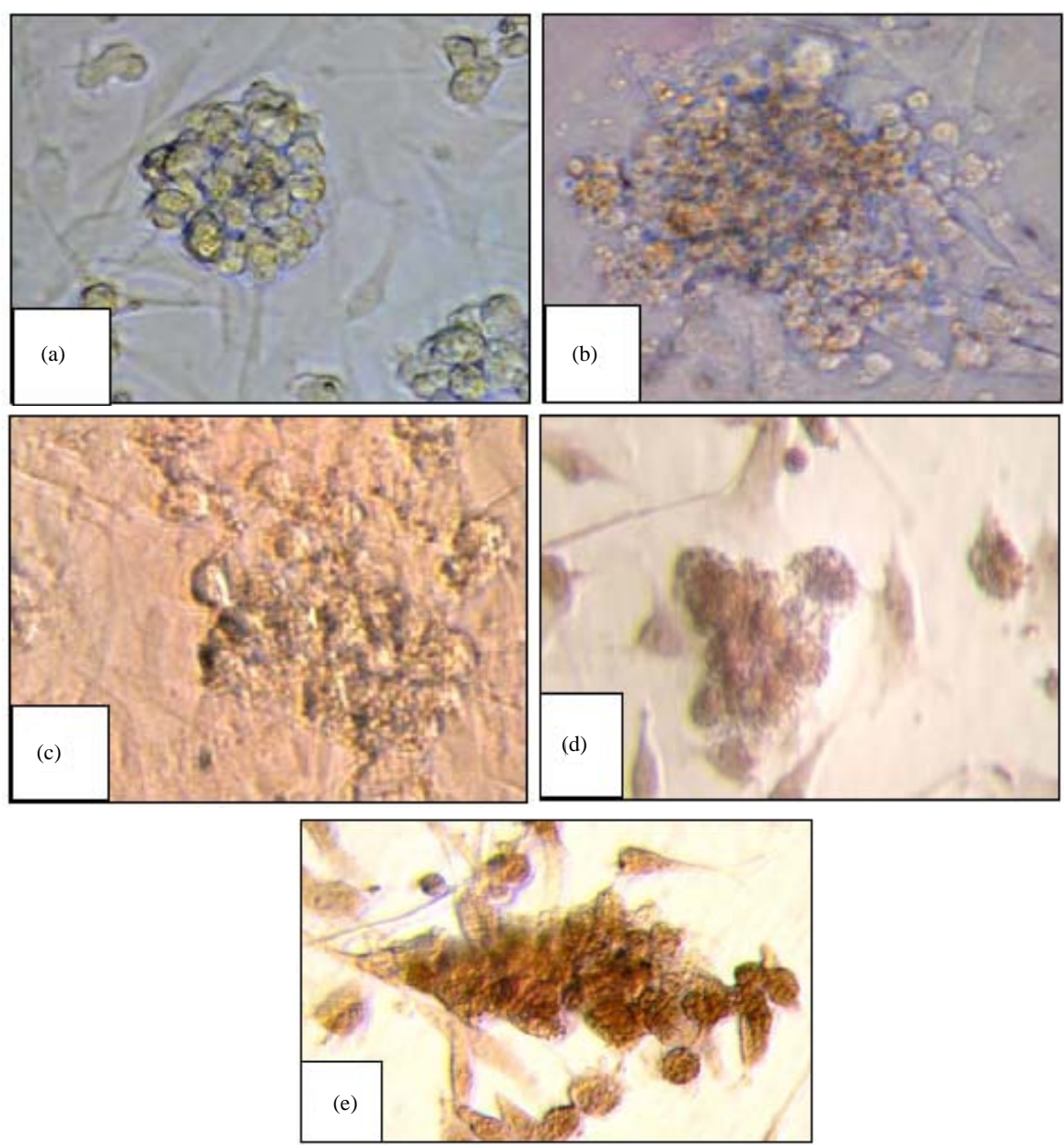

Fig. 1: Morphology of the chicken Gonadal Primordial Germ Cells (gPGCs) cultured in mitotically inactivated chicken fibroblastconditioned medium for: a) 12 days; b) 140 days; c) 280 days at a magnification of $400 \times$. The gPGCderived colonies were characterized by Periodic Acid-Schiff (PAS) staining at; d) Day 36; e) Passage 22 at a magnification of $400 \times$

The cytoplasm of chicken PGCs contains numerous glycogen granules. Therefore, PAS reaction which stains for glycogen had been used to identify PGCs (Meyer, 1964). The gPGC-derived colonies remained positively stained by PAS reaction throughout this study. The PAS reaction which stains for glycogen had been used to identify PGCs (Meyer, 1964).

Researchers found that the gPGCs but not gonadal stroma cells could be stained by PAS reaction. As shown in Fig. 1, cultured chicken PGC-derived colonies at primary culture (day 12, Fig. 1d) and passage 22 (Fig. 1e) could also be identified by PAS staining. Thus, researchers ensured that these colonies were derived from primordial germ cells but not gonadal stroma cells. The colonies derived from chicken gPGCs remained positive PAS staining throughout study. Their intensity to PAS staining did not decrease after repeated subculture. The cytoplasm of chicken PGCs contains numerous glycogen granules. Therefore, PAS reaction which stains for glycogen had been used to identify PGCs (Meyer, 1964). The gPGC-derived colonies remained positively stained by PAS reaction throughout this study. This implied that chicken gPGCs could maintain their original characteristics after long-term culture in CEF cells conditioned medium by repeated subcultures. Anti-SSEA1 antibody can specifically recognize galactose $(\beta 1-4)$ $\mathrm{N}$-acetylglucose-amine $(\alpha 1-3)$ fucose epitope which is a characteristic of undifferentiated murine ES and EG cells and has been used as a criterion for distinguishing pluripotent stem cells (Solter and Knowles, 1978).

In avian embryo development, it has been proven that avian germ cells (Karagence et al., 1996) and cultured 

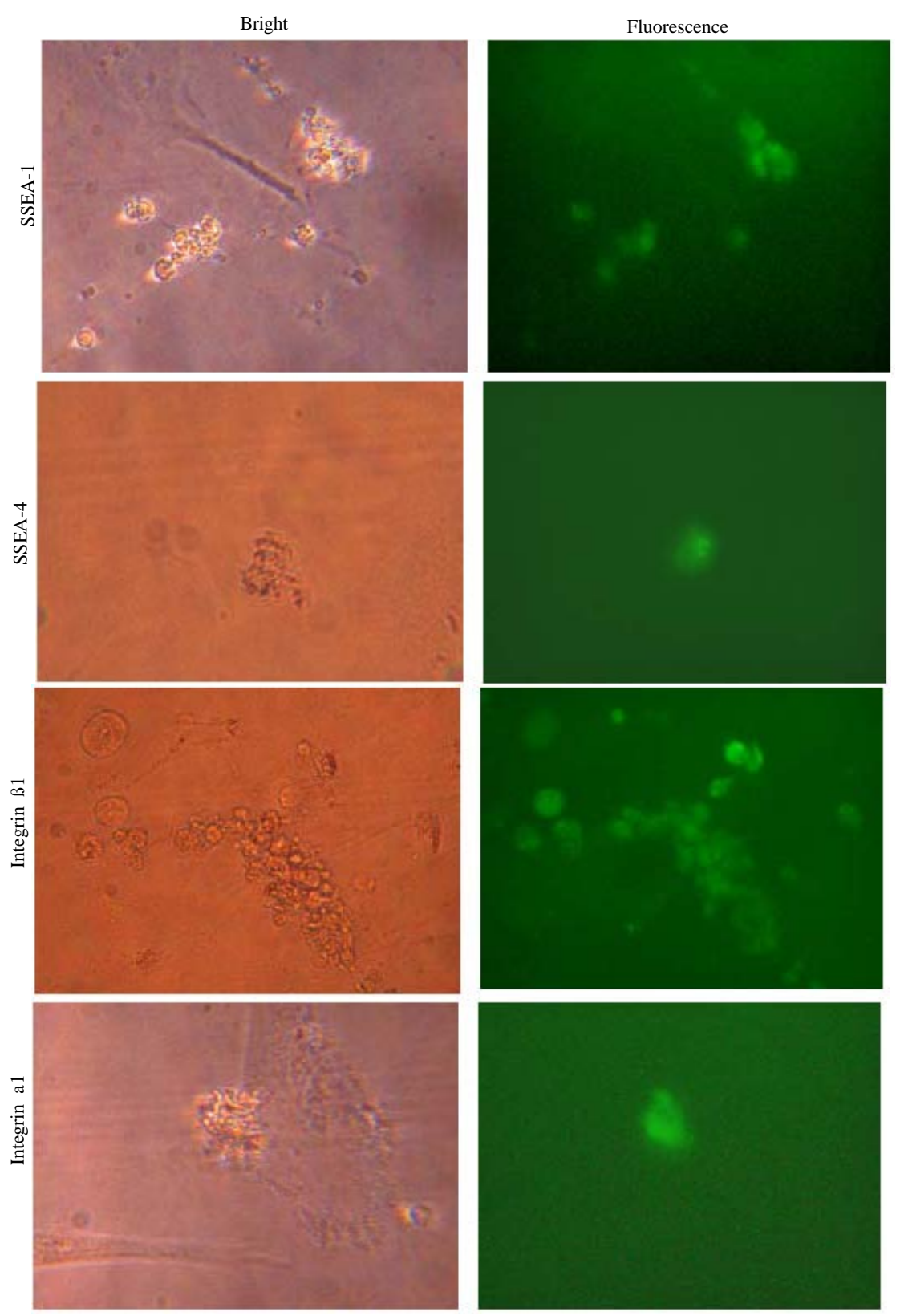

Fig. 2: Characterization of gPGC-derived colony at passage 22 by antibodies to SSEA-1, SSEA-4 integrin $\beta 1$ and integrin $\alpha 6$ at a magnification of $200 \times$

EG cells (Park and Han, 2000; Han et al., 2002) also express such epitopes on the cell surface. The cultured chicken gPGCs maintained in vitro for a long-term period might appear like EG cells and expressed cell markers specific for pluripotent stem cells (Han et al., 2002). In the present study, chicken gPGC-derived colonies but not the gonadal stroma cells maintained in the CEF cellsconditioned medium long-term in vitro culture system throughout the study were selectively stained by antibodies to SSEA-1, SSEA-4 integrin $\beta 1$ and integrin $\alpha 6$ (Fig. 2). These results suggested that these colonies maintained their capacity to express cell markers specific to pluripotent stem cells. Other than anti-SSEA-1 antibody, the results of immunostaining in this study also demonstrated that the antibodies to SSEA-1, SSEA-4 integrin $\alpha 6$ and integrin $\beta 1$ could specifically bind to chicken gPGCs as that described in the previous study (Jung et al., 2005) after cultured in vitro for 22 passages. 
These results suggested that the culture system established in the present study could maintain chicken gPGCs for longterm in vitro culture without losing the capacity to express cell markers specific to pluripotent cells. Alkaline phosphatase is a classic marker for the undifferentiated pluripotent cells of the mammalian species (Wobus et al., 1984; Matsui et al., 1992; Shim et al., 1997; Chen et al., 1999). Some reports also indicated that AP can be used to identify chicken PGCs (Tang and Zhang, 2007; Tang et al., 2007).

However, the AP activity in neither freshly isolated chicken gPGCs nor their deriving colonies could not be detected by standard staining protocol in this study. The same results had also been demonstrated elsewhere (Park and Han, 2000; Jung et al., 2005). This might be related to the physiological and genetic particularities of the avian species. The cultured chicken gPGCs maintained in vitro for a long-term period might appear like EG cells. However, the ultimate criteria of developmental potential must be determined by the in vivo test.

To elucidate the physiological details of gonadal migration of exogenous germ cells after transfer, researchers evaluated the EGFP-transfected gPGCs, cultured for 253 days (passage 18) (Fig. 3) CEF cellsconditioned medium were harvested and used for transplantation to the recipient embryos. Approximately $33 \%(15 / 45)$ and $40 \%(12 / 30)$ of embryos transplanted with EGFP-transfected and freshly isolated gPGCs, respectively, survived and hatched. At day 19
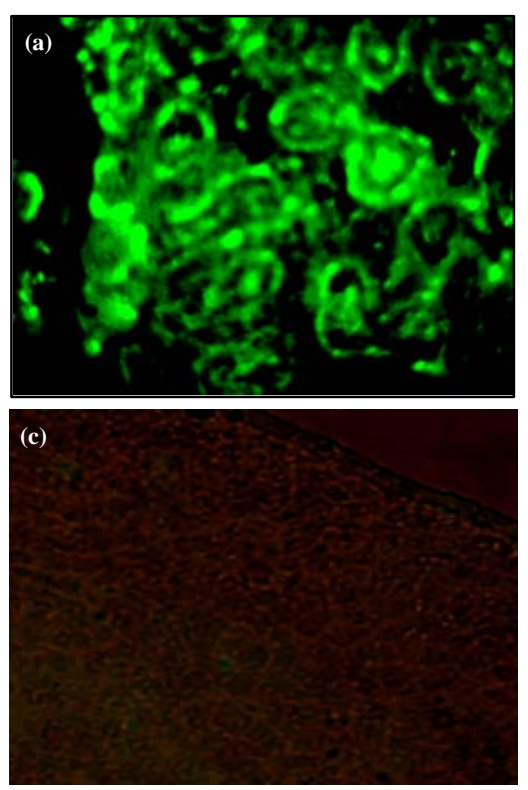

after hatching, their gonads were isolated for frozen dissection. The cells positive to EGFP-staining were found inside the seminiferous tubules from three individual chicks injected with EGFP-transfected PGCs (Fig. 4a). No EGFP-expressing cell was found from the gonadal dissections prepared from the control chicken (Fig. 4b).

The expression of the EGFP as revealed by rabbit anti-GFP polyclonal serum activity was detected in $13.5 \%$ of survival embryos (Table 1). The PCR product of the expected size (202 bp) was amplified from gonads of 19 days old chicken genomic DNA. The negative control genomic DNA was not amplified with the primer set for chicken (Fig. 5).

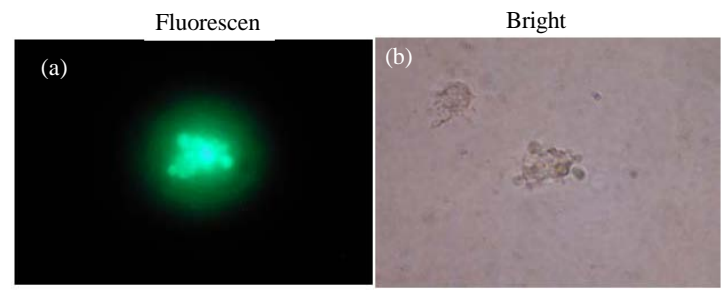

Fig. 3: EGFP-transfected gPGCs, cultured for 253 days: a) PGCs showing GFP under fluorescent microscope; b) Same colony of PGCs without fluorescent. Photos were taken under a fluorescence microscope at a magnification and Bright field of $200 \times$

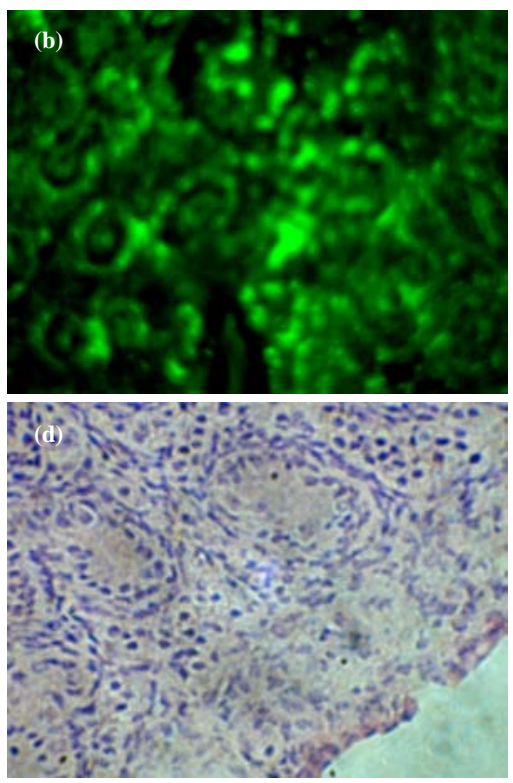

Fig. 4: The EGFP-expressing cells were detected inside the seminiferous tubules of the gonadal dissection of chicken; a, b) Derived from the embryo transplanted with EGFP transfected gPGCs not from chicken; c) Derived from the embryo transplanted with non-transfected gPGCs; d) $\mathrm{H}$ and $\mathrm{E}$ stain. Photos were taken under a fluorescence microscope at a magnification and Bright field of $400 \times$ 


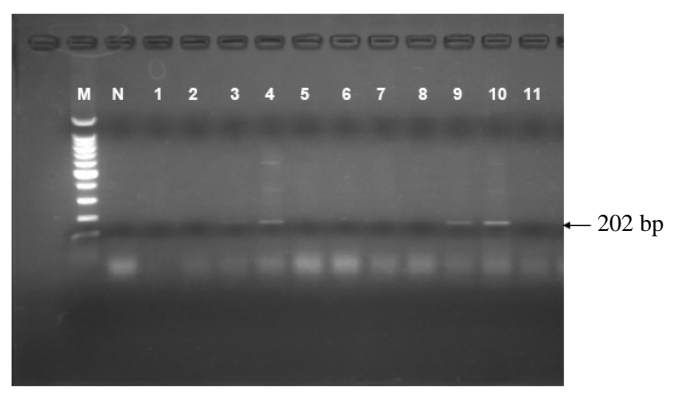

Fig. 5: PCR product of the expected size (202 bp) was amplified from gonads of 19 days old chicken genomic DNA. The negative control genomic DNA was not amplified with the primer set for chicken. M: Molecular size marker (100 bp). N: Negative control genomic DNA. 1 9: Injected with EGFPtransfected PGCs of the 19 days old chicks gonads genomic DNA. 10:GpEGFP-CMV plasmid DNA (positive control). 11: Deionized water

Table 1: The expression of the EGFP gene in gonads of 19 days old chicken by rabbit anti-GFP polyclonal serum

\begin{tabular}{lcc}
\hline Groups & No. of embryos observed & $\begin{array}{c}\text { No. of EGFP } \\
\text { expresised embryos (\%) }\end{array}$ \\
\hline Control & 20 & $0(00.0)$ \\
Trail & 37 & $5(13.5)$ \\
\hline
\end{tabular}

Table 2: Detect of $E G F P$ gene from gonads of 19 days old chicken genomic DNA by PCR $(\%)$

\begin{tabular}{lcc}
\hline Groups & No. of embryos detected & No. of detected EGFP (\%) \\
\hline Control & 20 & $0(00.0)$ \\
Trail & 51 & $8(15.7)$ \\
\hline
\end{tabular}

The rate of detected specific EGFP band from gonads of 19 days old chicken genomic DNA by PCR was $15.7 \%$ (Table 2).

Which resulted from the embryos transplanted EGFP transfected gPGCs. This result exhibited that the gPGCs after long-term in vitro culture still possessed the abilities of migration in blood stream integration into the germline and to participate the formation of the host gonads.

\section{CONCLUSION}

The results of the chicken gPGCs can be maintained in vitro for $>9$ months with medium conditioned by mitotically inactivated CEF. These EG-like cultured gPGCs are able to express cell markers specific to pluripotent cells and still capable of migration and reside in the embryonic gonads. This technique would be useful to provide numerous gPGCs and a wider time frame for genomic manipulation in the chicken.

\section{REFERENCES}

Allioli, N., J. Thomas, Y. Chebloune, V. Nigon, G. Verdier and C. Legras, 1994. Use of retrovial vectors to introduce and express the $\beta$-galactosidase marker gene in cultured chicken primordial germ cells. Dev. Biol., 165: 30-37.

Capecchi, M.R., 2001. Generating mice with targeted mutations. Nat. Med., 7: 1086-1090.

Chen, L.R., Y.L. Shiue, L. Bertolini, J.F. Merdrano, R.H. BonDurant and G.B. Anderson, 1999. Establishment of plurpotent cell lines from porcine preimplantation embryos. Theriogenology, 52: 195-212.

Eyal-Giladi, H., M. Ginsburg and A. Farbarow, 1981. Avian primordial germ cells are of epiblast origin. J. Embryol. Exp. Morphol., 65: 139-147.

Hamburger, V. and H. Hamilton, 1951. A series of normal stages in the development of the chick embryo. J. Morphol., 88: 49-92.

Han, J.Y., 2009. Germ cells and transgenesis in chickens. Comp. Immunol. Microbiol. Infect. Dis., 32: 61-80.

Han, J.Y., T.S. Park, J.H. Hong, D.K. Jeong, J.N. Kim, K.D. Kim and J.M. Lim, 2002. Production of germline chimeras by transfer of chicken gonadal primordial germ cells maintained in vitro for an extended period. Theriogenology, 58: 1531-1539.

Jung, J.G., D.K. Kim, T.S. Park, S.D. Lee, J.M. Lim and J.Y. Han, 2005. Development of novel markers for the characterization of chicken primordial germ cells. Stem Cell, 23: 689-698.

Karagence, L., Y. Cinnamon, M. Ginsburg and J.N. Petitte, 1996. Origin of primoedial germ cells in the prestreak chick embryo. Dev. Genet., 19: 290-301.

Lillico, S.G., M.J. McGrew, A. Sherman and H.M. Sang, 2005. Transgenic chickens as bioreactors for proteinbased drugs. Drug Discov. Today, 10: 191-196.

Matsui, Y., K. Zsebo and B.L. Hogan, 1992. Derivation of pluripotential embryonic stem cells from murine primordial germ cells in culture. Cell, 70: 841-847.

Meyer, D.B., 1964. The migration of primordial germ cells in the chick embryo. Dev. Biol., 10: 154-190.

Naito, M., E. Sasaki, M. Ohtaki and M. Sakurai, 1994a. Introduction of exogenous DNA into somatic and germ cells of chickens by microinjection into the germ cell disc of fertalized ova. Mol. Reprod. Dev., 37: $167-171$.

Naito, M., A. Tajima, Y. Yasuda and T. Kuwana, 1994b. Production of germline chimeric chickens, with high transmission rate of donor-derived gametes, produced by transfer of primordial germ cells. Mol. Reprod. Dev., 39: 153-161. 
Park, T.S. and J.Y. Han, 2000. Derivation and characterization of pluripotent embryonic germ cells in chicken. Mol. Reprod. Dev., 56: 475-482.

Park, T.S., D.K. Jeong, J.N. Kim, G.H. Song, Y.H. Hng, M. Lim and J.Y. Han, 2003. Improved germline transmission in chichen chimera produced by transplantation of gonadal primordial germ cells into recipient embryos. Biol. Reprod., 68: 1657-1662.

Park, T.S., M.A. Kim, J.M. Lim and J.Y. Han, 2008. Production of quail (Coturnix japonica) germline chimeras derived from in vitro-cultured gonadal primordial germ cells. Mol. Reprod. Dev., 75: 274-281.

Petitte, J., M.E. Vlark, A.M. Gibbins and R.J. Etches, 1990. Production of somatic and germline chimeras of chicken by transfer of early blastodermal cells. Development, 108: 185-189.

Shim, H., A. Gutierrez-Adan, L.R. Chen, R.H. BonDurant, E. Behboodi and G.B. Anderson, 1997. Isolation of pluripotent stem cells from cultured porcine primordial germ cells. Biol. Reprod., 57: 1089-1095.
Shin, S.S., T.M. Kim, S.Y. Kim, T.W. Kim and H.W. Seo et al., 2008. Generation of transgenic quail through germ cell-mediated germline transmission. FASEB J., 22: 2435-2444.

Solter, D. and B.B. Knowles, 1978. Monoclonal antibody defining a stage-specific mouse embryonic antigen (SSEA-1). Proc. Natl. Acad. Sci. USA., 75: 5565-5569.

Tang, X. and C. Zhang, 2007. Activation of protein kinases $\mathrm{A}$ and $\mathrm{C}$ promoted proliferation of chicken primordial germ cells. Anim. Reprod. Sci., 101: 295-303.

Tang, X., C. Zang, Y. Jin, C. Ge and Y. Wu, 2007. Proproliferating effect of homologous somatic cells on chicken primordial germ cells. Cell Biol. Int., 31: 1016-1021.

Wentworth, B.C., H. Tsai, J.H. Hallett, D.S. Godzales and G. Rajcic-Spasojevic, 1988. Manipulation of avian primordial germ cells and gonadal differentiation. Poult. Sci., 68: 999-1010.

Wobus, A.M., H. Holzhausen, P. Jakel and J. Schoneich, 1984. Characterization of a pluripotent stem cell line derived from a mouse embryo. Exp. Cell Res., 152: $212-219$. 